\title{
Effects of Treadmill Gait Training According to Different Inclination on Postural Balance in Patients with Chronic Stroke
}

\author{
Myeong Su Choi', Jong Su Lee', Kyoung Kim², Young Mi Kim \\ 'Graduate Student, Department of Rehabilitation Science, Graduate school, Daegu University; ${ }^{2}$ Professor, Department of Physical Therapy, College \\ of Rehabilitation Science, Daegu University, Daegu, Korea
}

Purpose: This study was to examine the effects of treadmill gait training at different controlled inclinations on the standing balance of hemiplegic patients caused by cerebrovascular injury.

Methods: The study's subjects were 44 patients with chronic stroke, randomly divided into three experimental groups: $0^{\circ}$ treadmill gait training $(n=14), 5^{\circ}$ treadmill gait training $(n=15)$, and $10^{\circ}$ treadmill gait training $(n=15)$. In addition to conventional physical therapy, the subjects underwent gait training on a treadmill with one of three different inclinations for 30 min per session five times per week for six weeks. The Biodex balance system SD, Berg balance scale, and timed up and go tests were used to measure the postural balance of the patients.

Results: This study showed that gait training on a treadmill at controlled inclinations of $0^{\circ}, 5^{\circ}$, and $10^{\circ}$ positively influenced the stroke patients' standing balance. The $5^{\circ}$ and $10^{\circ}$ inclination gait training groups showed significantly more improvement than the $0^{\circ}$ inclination group.

Conclusion: Gait training on a treadmill with inclinations of $0^{\circ}, 5^{\circ}$, or $10^{\circ}$ can be said to positively affect the postural balance of hemiplegic patients due to stroke. In particular, $5^{\circ}$ and $10^{\circ}$ inclination gait training offered more significant improvement than the $0^{\circ}$ inclination gait training group. When added to regular treatment routines, gait training at controlled inclinations is an effective intervention for improving hemiplegia due to postural balance.

Keywords: Stroke, Postural balance, Gait

\section{INTRODUCTION}

Stroke is caused by cerebrovascular bleeding when a vessel supplying blood to the brain is clogged. Patterns of disability due to stroke vary according to the areas of the brain damaged and the degree of damage and usually include hemiplegia of the limbs, sensory impairment, cognitive disorder, and perceptual disturbances. ${ }^{1,2}$ In particular, stroke patients show increases in the asymmetry of standing postures because of changes due to the compensatory strategy for the non-paretic lower limb. In addition, the weight bearing becoming biased toward the non-paretic lower limb negatively affects overall body motions. When the weight is shifted toward the paretic side for symmetric alignment, abnormal muscle tension and move-

Received Nov 13, 2018 Revised Dec 18, 2018

Accepted Dec 26, 2018

Corresponding author Jong Su Lee

E-mail jjongsu2@naver.com ment patterns occur, making motor control more difficult and leading to postural deficits. ${ }^{3}$ This asymmetrical postural control caused by the imbalance in muscle strength increases the risk of falling toward the paretic side in the case of sudden postural fluctuations. ${ }^{4}$

As the necessity of task-oriented programs for gait training after stroke has become recognized, attention to the decline of endurance of patients has been increasing, leading to an emphasis on the necessity of gait training programs to improve physical condition and reduce abnormal energy expenditure due to the paralysis. ${ }^{5,6}$ In relation to this necessity, treadmill training, which is effective for muscle strengthening, balance, and re-recognition of the motor control for gait patterns of stroke patients, has an advantage by enabling not only accurate understanding of motion loads but also in the appli-

Copylight (C2018 The Korea Society of Physical Therapy

This is an Open Access article distribute under the terms of the Creative Commons Attribution Non-commercial License (Http:// creativecommons.org/license/by-nc/4.0.) which permits unrestricted non-commercial use, distribution, and reproduction in any medium, provided the original work is properly cited. 
cation of the same load in the case of repeated measurements because it allows motor load control with changes in gait velocity or inclinations. ${ }^{5-7}$ As another program to improve stroke patients' walking functions, slope gait training induces increases in the flexion angles of the hip joint, knee joint, and ankle joint during the initial stance phase and swing phase of the paretic lower limb of the stroke patient, ${ }^{8}$ which can increase the entire range of motion of the ankle joint along with increases in the degree of inclination and is effective for increases in plantar pressure.

Previous studies have indicated that gait training on inclined treadmills can be helpful for postural balance in stroke patients because it can activate the trunk and lower limb muscles that were unable to be used due to paralysis. ${ }^{10}$ In this respect, the purpose of this study was to investigate the effects of treadmill gait training using adjusted degrees of inclination on the postural balance of stroke patients.

\section{METHODS}

\section{Subjects}

The subjects of this study were 45 patients who had been diagnosed as having had a stroke and who were (1) hospitalized for at least six months, (2) without orthopedic or cardiopulmonary diseases, and (3) able to walk independently for at least 30m indoors, (4) a patient with a clear level of consciousness to understand the researcher's instructions. They were randomly divided into three groups of treadmill training using $0^{\circ}, 5^{\circ}$, or $10^{\circ}$ of slope ( $\mathrm{n}=15$ for each group). Each group received a 30-min physical therapy session based on the concept of neurophysiological treatment as well as a 30-min walking training session on the treadmill three times a week for six weeks. The same investigators measured the subjects' postural balance before and after training using measurement devices. All subjects un- derstood the content of this study based on the ethical principles of the Declaration of Helsinki and submitted written consents as volunteers.

One patient in the group of $0^{\circ}$ was discharged from the hospital, so 44 subjects participated in the study to the end. For the group using $0^{\circ}$ inclination $(\mathrm{n}=14)$, the mean age was $62.1 \pm 5.9$ years, the mean height was $160.8 \pm 9.1 \mathrm{~cm}$, the mean body weight was $61.4 \pm$ $10.7 \mathrm{~kg}$, and the mean walking speed for $10 \mathrm{~m}$ was $0.5 \pm 0.2 \mathrm{~m} / \mathrm{s}$. For the group using $5^{\circ}$ inclination $(\mathrm{n}=15)$, the mean age was $56.5 \pm 9.8$ years, the mean height was $165.5 \pm 6.9 \mathrm{~cm}$, the mean weight was 67.0 $\pm 8.9 \mathrm{~kg}$, and the mean walking speed for $10 \mathrm{~m}$ was $0.5 \pm 0.1 \mathrm{~m} / \mathrm{s}$. For the group using $10^{\circ}$ inclination $(n=15)$, the mean age was $57.5 \pm$ 5.5 years, the mean height was $163.5 \pm 9.6 \mathrm{~cm}$, the mean weight was $59.1 \pm 10.3 \mathrm{~kg}$, and the mean walking speed for $10 \mathrm{~m}$ was $0.5 \pm 0.2 \mathrm{~m} / \mathrm{s}$. There were no significant differences in the general characteristics of the subjects between groups ( $p>0.05$ ). The demographic information for each group is presented in Table 1 .

\section{Experimental methods}

\section{1) Procedure}

We increased the walking speed on the treadmills in a gradual way such that it did not curtail independence or stability in walking. During a pre-test, subjects walked for $10 \mathrm{~m}$ at different speeds (from $1.5 \mathrm{~km} / \mathrm{h}$ to $2.5 \mathrm{~km} / \mathrm{h}$ ) until a speed was reached where stability could be maintained. Then, each subject walked at that measured speed on a $0^{\circ}, 5^{\circ}$, or $10^{\circ}$ slope, according to their assigned group, for their training sessions. To reduce associated reactions that could be induced by walking, the subjects used both hands to grip the front handles of the treadmill, those who could not use one hand had that hand fixed on the handle with a strap. The patients were assisted in their slope walking by a skilled physical therapist.

Table 1. General characteristic of the subject

\begin{tabular}{|c|c|c|c|c|c|}
\hline & & $0^{\circ}$ group $(n=14)$ & $5^{\circ}$ training $(n=15)$ & $10^{\circ}$ training $(n=15)$ & $\mathrm{p}$ \\
\hline Gender & $\mathrm{M} / \mathrm{F}$ & $9 / 5$ & $7 / 8$ & $8 / 7$ & 0.38 \\
\hline Age (year) & & $62.1 \pm 5.9$ & $56.5 \pm 9.8$ & $57.5 \pm 5.5$ & 0.13 \\
\hline High $(\mathrm{cm})$ & & $160.8 \pm 9.1$ & $165.5 \pm 6.9$ & $163.5 \pm 9.6$ & 0.37 \\
\hline Weight (kg) & & $61.4 \pm 10.7$ & $67.0 \pm 8.9$ & $59.1 \pm 10.3$ & 0.88 \\
\hline Onset (mon) & & $28.6 \pm 9.6$ & $30.7 \pm 8.5$ & $28.5 \pm 11.9$ & 0.20 \\
\hline Paretic side & RT/LT & $7 / 7$ & $8 / 7$ & $6 / 9$ & 0.63 \\
\hline $10 \mathrm{~m}$ walking test $(\mathrm{m} / \mathrm{s})$ & & $0.5 \pm 0.2$ & $0.5 \pm 0.1$ & $0.5 \pm 0.2$ & 0.60 \\
\hline
\end{tabular}

$\mathrm{M} \pm \mathrm{SD}$ : mean \pm standard deviation, $\mathrm{M}$ : male, F: female, RT: right, LT: left. 


\section{2) Measurement}

(1) Balance system

For the evaluation of the balance position, the Biodex balance system SD (Biodex Medical System, Inc., Shirley, NY, USA)(figure 1) was used. The test was run for $30 \mathrm{~s}$, and the test application levels of the mat were 1-9, where 1 was the most common movement, and 9 was the least common movement. Because this study targeted patients with central nervous system injuries, the test was conducted at the lowest level, 9, which, representing the least amount of movement, had the lowest risk factor. Balance ability was captured as a balance index value, where the better an individual's balance ability, the lower the balance index. As part of the assessment program, we also measured the overall stability index (OSI), the anteroposterior stability index (ASI), and the mediolateral stability index (MSI). Before the test, the patient stood on a fixed mat on both feet and exercised three times to adjust to the equipment, after which the test was started. The subjects were measured at the position where their feet were comfortably open and both their hands were on the equipment. Three measurements were taken, and the results were averaged.

The Berg balance scale (BBS) and timed up and go (TUG) tests were used to measure the dynamic standing balance of the patients.

\section{Statistical analysis}

IBM SPSS Statistics 20.0 software (IBM, Armonk, NY, USA) was used for statistical processing of the results obtained from this study to analyze the effect of treadmill gait training on standing balance in patients with chronic stroke. For the physical characteristics of each group and the measurement data of each variable, the mean and the standard deviation were calculated, and the normality test using the residuals of the result data was confirmed by the ShapiroWilk test. One-way ANOVA was used to analyze the general characteristics of the three groups. A paired t-test was performed to determine the changes in standing balance before and after intervention in each group. One-way ANOVA was used to compare the differences in postural balance before and after intervention in each group, and least square difference (LSD) was used for the post-hoc test. The significance level $(\alpha)$ of all statistics was set to 0.05 .

\section{RESULTS}

All three groups showed a significant decrease in the comparison test of OSI between pre- and post-training $(\mathrm{p}<0.05)$. The variation test of OSI between pre- and post-training revealed a significant difference $(\mathrm{p}<0.05)$. The post-test LSD showed significant differences between the $0^{\circ}$ and the $5^{\circ}$ groups and between the $0^{\circ}$ and $10^{\circ}$ groups $(\mathrm{p}<0.05)$.

In the comparison test of the ASI of each group between pre- and post-training, the $5^{\circ}$ and $10^{\circ}$ groups showed a significant difference
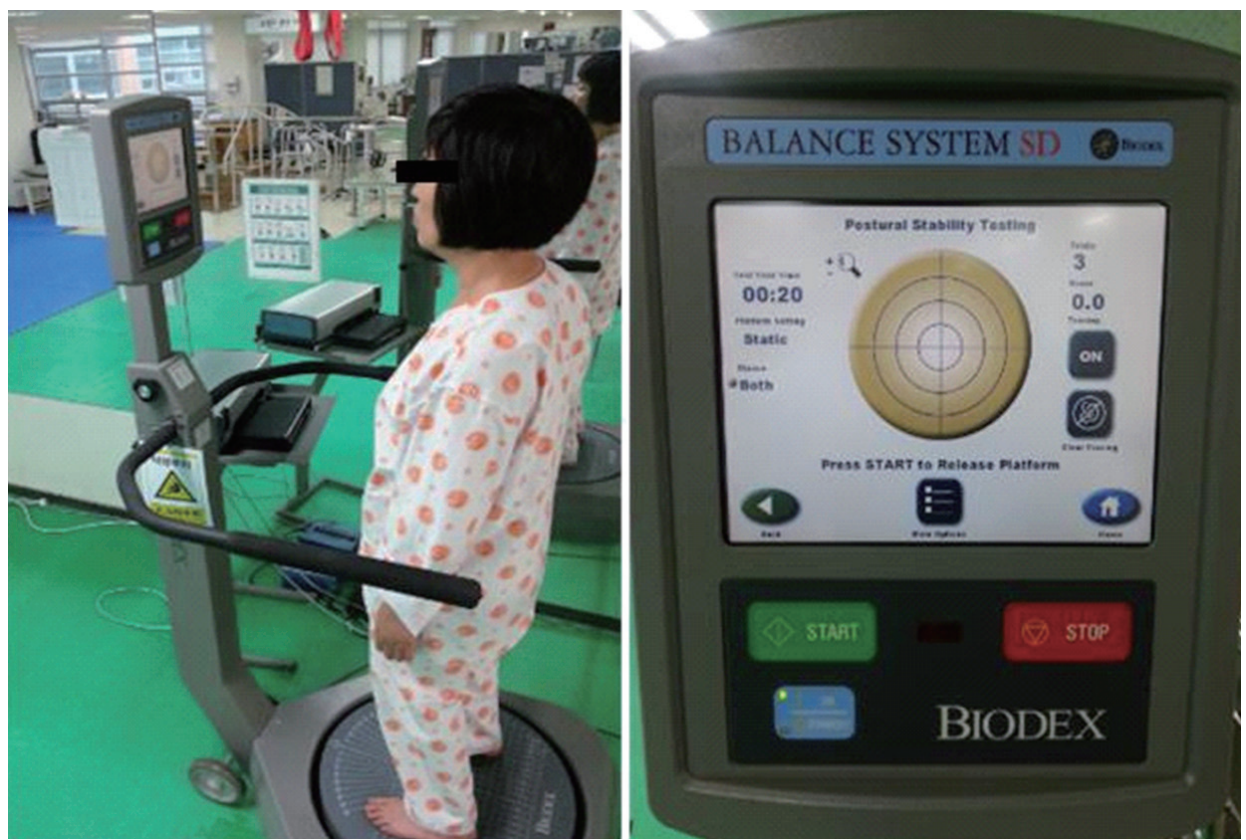

Figure 1. Biodex balance system SD (Biodex Medical System, Inc., Shirley, NY, USA). 
Table 2. The comparison of mean for standing balance between pre and post value for the three groups

\begin{tabular}{|c|c|c|c|c|c|}
\hline & & Pre-value & Post-value & t & $n$ \\
\hline & & & & l & 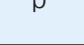 \\
\hline OSI & $0^{\circ}$ Training & $2.01 \pm 0.99$ & $1.35 \pm 0.22$ & 2.58 & $0.02^{*}$ \\
\hline & $5^{\circ}$ Training & $1.93 \pm 0.53$ & $0.58 \pm 0.78$ & 7.91 & $0.00^{* *}$ \\
\hline & $10^{\circ}$ Training & $1.94 \pm 1.05$ & $0.74 \pm 0.50$ & 3.75 & $0.00^{* *}$ \\
\hline & $\mathrm{t}$ & 0.03 & 7.00 & & \\
\hline & $p$ & 0.96 & $0.00^{* *}$ & & \\
\hline ASI & $0^{\circ}$ Training & $1.26 \pm 1.03$ & $0.97 \pm 0.92$ & 0.98 & 0.45 \\
\hline & $5^{\circ}$ Training & $1.15 \pm 0.45$ & $0.38 \pm 0.21$ & 6.63 & $0.00^{* *}$ \\
\hline & $10^{\circ}$ Training & $1.25 \pm 0.86$ & $0.40 \pm 0.32$ & 3.18 & $0.00^{* *}$ \\
\hline & $\mathrm{t}$ & 0.08 & 5.15 & & \\
\hline & $\mathrm{p}$ & 0.92 & $0.01^{*}$ & & \\
\hline MSI & $0^{\circ}$ Training & $0.97 \pm 0.76$ & $0.64 \pm 0.36$ & 1.77 & 0.09 \\
\hline & $5^{\circ}$ Training & $0.52 \pm 0.21$ & $0.34 \pm 0.17$ & 3.76 & $0.00^{* *}$ \\
\hline & $10^{\circ}$ Training & $0.85 \pm 1.43$ & $0.47 \pm 0.30$ & 1.08 & 0.29 \\
\hline & $\mathrm{t}$ & 0.88 & 4.03 & & \\
\hline & $p$ & 0.42 & $0.02^{*}$ & & \\
\hline BBS & $0^{\circ}$ Training & $38.71 \pm 8.85$ & $42.57 \pm 4.94$ & 2.21 & $0.04^{*}$ \\
\hline & $5^{\circ}$ Training & $43.53 \pm 6.54$ & $49.93 \pm 6.06$ & 8.70 & $0.00^{* *}$ \\
\hline & $10^{\circ}$ Training & $39.26 \pm 7.83$ & $48.26 \pm 7.12$ & 6.53 & $0.00^{* *}$ \\
\hline & $\mathrm{t}$ & 1.69 & 5.68 & & \\
\hline & $\mathrm{p}$ & 0.19 & $0.00^{\star *}$ & & \\
\hline TUG & $0^{\circ}$ Training & $26.71 \pm 9.81$ & $24.21 \pm 10.37$ & 2.28 & $0.03^{*}$ \\
\hline & $5^{\circ}$ Training & $20.13 \pm 8.49$ & $16.60 \pm 6.08$ & 3.84 & $0.00^{* *}$ \\
\hline & $10^{\circ}$ Training & $28.00 \pm 14.38$ & $19.53 \pm 7.78$ & 3.36 & $0.00^{* *}$ \\
\hline & $\mathrm{t}$ & 2.10 & 3.15 & & \\
\hline & $\mathrm{p}$ & 0.13 & 0.05 & & \\
\hline
\end{tabular}

$\mathrm{M} \pm \mathrm{SD}$ : mean \pm standard deviation, ${ }^{*} \mathrm{p}<0.05,{ }^{* *} \mathrm{p}<0.01$

OSI: overall stability Index, ASI: anteroposterior stability Index, MSI: mediolateral stability Index, BBS: Berg balance scale, TUG: timed up and go.

$(\mathrm{p}<0.05)$, while the $0^{\circ}$ groups $\operatorname{did} \operatorname{not}(\mathrm{p}>0.05)$. The variation test of ASI between pre- and post-training revealed a significant difference $(\mathrm{p}<0.05)$. The post-test LSD based on exercise patterns of the three groups revealed significant differences between the $0^{\circ}$ and $5^{\circ}$ groups and between the $0^{\circ}$ and $10^{\circ}$ groups $(\mathrm{p}<0.05)$.

In the comparison test of the MSI of each group between preand post-training, the $5^{\circ}$ group showed significant differences $(\mathrm{p}<0.05)$, while the $0^{\circ}$ and $10^{\circ}$ groups did not $(\mathrm{p}>0.05)$. The variation test of MSI between pre- and post-training revealed a significant difference $(\mathrm{p}<0.05)$. The post-test LSD based on exercise patterns of the three groups revealed significant differences between the $0^{\circ}$ and $5^{\circ}$ groups $(\mathrm{p}<0.05)$.

All three groups showed a significant increase in the comparison test of BBS scores between pre- and post-training $(\mathrm{p}<0.05)$. Similarly, the variation test of BBS scores between pre- and post-training revealed a significant difference $(\mathrm{p}<0.05)$, and the post-test LSD showed significant differences between the $0^{\circ}$ and $5^{\circ}$ groups and between the $0^{\circ}$ and $10^{\circ}$ groups $(\mathrm{p}<0.05)$.

All three groups showed a significant decrease in the comparison test of TUG test results between pre- and post-training $(\mathrm{p}<0.05)$. The variation test of TUG test results between pre- and post-training revealed no significant difference $(\mathrm{p}>0.05)($ Table 2,3$)$.

\section{DISCUSSION}

This study was conducted for six weeks to examine the effects of adjustments to treadmill inclination on the postural balance of chronic stroke patients.

The values of OSI showed significant differences three groups $(\mathrm{p}<0.05)$ and values of OSI showed significant differences $5^{\circ}$ and $10^{\circ}$ groups $(\mathrm{p}<0.05)$. In previous studies, findings indicated that treadmill training led to increases in the weight shift distance from 
Table 3. LSD test of $\mathrm{OBI}, \mathrm{ABI}, \mathrm{MBI}, \mathrm{BBS}$ on each group

(Unit :score)

\begin{tabular}{|c|c|c|c|c|c|}
\hline & Intervention & Intervention & $\mathrm{MD}$ & SE & $p$ \\
\hline \multirow[t]{3}{*}{ OSI } & $0^{\circ}$ Group & $5^{\circ}$ Training & 0.77 & 0.21 & $0.00^{* *}$ \\
\hline & $5^{\circ}$ Training & $10^{\circ}$ Training & -0.16 & 0.21 & 0.44 \\
\hline & $10^{\circ}$ Training & $0^{\circ}$ Group & -0.61 & 0.21 & $0.00^{* *}$ \\
\hline \multirow[t]{3}{*}{ ASI } & $0^{\circ}$ Group & $5^{\circ}$ Training & 0.59 & 0.21 & $0.00^{* *}$ \\
\hline & $5^{\circ}$ Training & $10^{\circ}$ Training & -0.02 & 0.20 & 0.92 \\
\hline & $10^{\circ}$ Training & $0^{\circ}$ Group & -0.57 & 0.21 & $0.00^{* *}$ \\
\hline \multirow[t]{3}{*}{ MSI } & $0^{\circ}$ Group & $5^{\circ}$ Training & 0.3 & 0.10 & $0.00^{* *}$ \\
\hline & $5^{\circ}$ Training & $10^{\circ}$ Training & -0.13 & 0.10 & 0.21 \\
\hline & $10^{\circ}$ Training & $0^{\circ}$ Group & -0.16 & 0.10 & 0.11 \\
\hline \multirow[t]{3}{*}{ BBS } & $0^{\circ}$ Group & $5^{\circ}$ Training & -7.36 & 2.27 & $0.00^{* *}$ \\
\hline & $5^{\circ}$ Training & $10^{\circ}$ Training & 1.66 & 2.24 & 0.46 \\
\hline & $10^{\circ}$ Training & $0^{\circ}$ Group & 5.69 & 2.27 & $0.01^{*}$ \\
\hline
\end{tabular}

$\mathrm{M} \pm$ SD: mean \pm standard deviation, ${ }^{*} \mathrm{p}<0.05,{ }^{* *} \mathrm{p}<0.01$.

OSI: overall stability Index, ASI: anteroposterior stability Index, MSI: mediolateral stability Index, BBS: Berg balance scale, TUG: timed up and go.

the paretic side to the non-paretic side and was effective for balance improvement. ${ }^{11}$ They also showed that the activity of the gluteus maximus, rectus femoris, vastus medialis, and gastrocnemius muscles increased during ramp ascension. ${ }^{12}$ In this study, too, the trunk muscles and lower limb muscles for balance were activated through treadmill gait training with adjustment of the degree of inclination, and this is thought to have led to decreases in the postural sway index.

In the post-hoc test of differences in the OSI and the ASI before and after training, the between $0^{\circ}$ and $5^{\circ}$ groups and $0^{\circ}$ and $10^{\circ}$ groups showed significant differences. In a study conducted by $\mathrm{kim}^{7}$ the flexion of the hip joint and knee joint generally increased on the sagittal plane, and the dorsal flexion of the ankle joint increased at each phase of the gait cycle during ramp ascension as compared to flatland walking. In this study, too, the decreases in the movement on the sagittal plane during walking on the $5^{\circ}$ or $10^{\circ}$ inclination ramps, as compared to walking on the $0^{\circ}$ inclination ramps, seems to have affected the decreases in the OSI and ASI, and the differences between the two degrees of inclination seem to be insignificant. However, it was identified that slope walking is more effective than $0^{\circ}$ inclination walking.

The values of MSI revealed significant differences between the $0^{\circ}$ and the $5^{\circ}$ inclination groups $(\mathrm{p}<0.05)$. Previous studies on stroke patients' treadmill gait training reported increases in stride and gait velocity thanks to increases in the weight bearing of the paretic lower limb before and after gait training, ${ }^{13}$ and in this study, too, increases in the mediolateral stability before and after gait training were identified in the $5^{\circ}$ inclination training group. However, no significant difference between before and after gait training could be seen in the $10^{\circ}$ inclination training group. This is considered attributable to the fact that movements on the sagittal plane (adduction of the hip joint at the time point of paretic lower limb heel strike, abduction of the hip joint at the time point of toe taking off, adduction of the hip joint during the swing phase, adduction of the knee joint at the time point of paretic lower limb heel strike, and inversion of the ankle joint during the entire gait cycle) during walking on the $10^{\circ}$ inclination are larger than those during walking on the $5^{\circ}$ inclination, so the weight bearing by the non-paretic side is greater.

The resultant values of the BBS scores show significant differences between the $0^{\circ}$ and $5^{\circ}$ inclination groups and between the $0^{\circ}$ and $10^{\circ}$ inclination groups $(\mathrm{p}<0.05)$. The BBS items are scales for the evaluation of static standing balance ability and dynamic standing balance ability. Through the scores, it was found that treadmill gait training improved static standing ability and also contributed to the improvement of dynamic standing ability. The difference in the values of TUG between pre- and post-training was not significant $(\mathrm{p}>0.05)$. Treadmill training has increased weight support to paretic side, improving balance and walking and it is believed that the speed and regularity of walking are enhanced by strengthening of the lower extremities and increasing the forward and backward sloping motion of the pelvis. When the above results are combined, inclined treadmill gait training can be said to have good effects on the dynamic balance ability of stroke patients.

In this study, treadmill gait training with adjustment to the de- 
gree of inclination showed effective improvement of the dynamic and static balance abilities of chronic stroke patients. In addition, in statistical analysis of differences among the three training groups, the $5^{\circ}$ and $10^{\circ}$ inclination training groups showed significant differences from the $0^{\circ}$ inclination training group. Given the foregoing results, treadmill gait training with adjustment of the degree of inclination can be expected to be effective as an appropriate intervention for chronic stroke patients with impaired postural balance.

The limitations of this study include the relatively short intervention period and the failure to conduct continuous evaluations. And due to the small number of patients, the standard deviation in the group is large, which is limited in generalization. In future studies, attention should be paid to the fact that as the degree of inclination increases, compensatory movements for the flexion of the lower limb joints are more likely to be induced so that correct postures and exercise methods can be applied to training.

In conclusion, gait training on a treadmill with inclinations of $0^{\circ}$, $5^{\circ}$, or $10^{\circ}$ can be said to positively affect the postural balance of hemiplegic patients due to stroke. In particular, $5^{\circ}$ and $10^{\circ}$ inclination gait training offered more significant improvement than the $0^{\circ}$ inclination gait training group. When added to regular treatment routines, gait training at controlled inclinations is an effective intervention for improving hemiplegia due to postural balance.

Gait training on an inclined treadmill is effective for improvement of the postural balance of chronic stroke patients, and if correct postures and exercise methods are combined with training to control the compensatory movement for the flexion of lower limb joints, the intervention will be more effective

\section{REFERENCES}

1. Mercier L, Audet T, Hebert R et al. Impact of motor, cognitive, and perceptual disorders on ability to perform activities of daily living after stroke. Stroke. 2001;32(11):2602-8.

2. Ozdemir F, Birtane M, Tabatabaei R et al. Comparing stroke rehabilitation outcomes between acute inpatient and nonintense home settings. Arch Phys Med Rehabil. 2001;82(10):1375-9.

3. de Haart M, Geurts AC, Huidekoper SC et al. Recovery of standing balance in postacute stroke patients: a rehabilitation cohort study. Arch Phys Med Rehabil. 2004;85(6):886-95.

4. Ikai T, Kamikubo T, Takehara I et al. Dynamic postural control in patients with hemiparesis. Am J Phys Med Rehabil. 2003;82(6):463-9.

5. Dean CM, Richards CL, Malouin F. Task-related circuit training improves performance of locomotor tasks in chronic stroke: a randomized, controlled pilot trial. Arch Phys Med Rehabil. 2000;81(4):409-17.

6. Macko RF, Smith GV, Dobrovolny CL et al. Treadmill training improves fitness reserve in chronic stroke patients. Arch Phys Med Rehabil. 2001; 82(7):879-84.

7. Kim J. The kinematic and kinetic analysis of treadmill gait with various inclination and speed. Seoul, Ewha Womans University, 2000.

8. Moreno CC, Mendes LA, Lindquist AR. Effects of treadmill inclination on the gait of individuals with chronic hemiparesis. Arch Phys Med Rehabil. 2011;92(10):1675-80.

9. Kim TH, Kim BG. The change of plantar pressure and range of motion of ankle joint according to treadmill gradients. Korean J Orthop Manu Ther. 2008;14(1):39-47.

10. Kim BG, Gong WT, Jung YW. The myoelectrical activities of trunk muscle and quardriceps femoris according to treadmill gait different inclination and speeds. Korean J Orthop Manu Ther. 2007;13(1):44-57.

11. Jonsson E, Henriksson M, Hirschfeld H. Does the functional reach test reflect stability limits in elderly people? J Rehabil Med. 2003;35(1):26-30.

12. Lay AN, Hass CJ, Richard Nichols T et al. The effects of sloped surfaces on locomotion: an electromyographic analysis. J Biomech. 2007;40(6): 1276-85.

13. Hesse $S$, Werner C, Paul T et al. Influence of walking speed on lower limb muscle activity and energy consumption during treadmill walking of hemiparetic patients. Arch Phys Med Rehabil. 2001;82(11):1547-50. 